\title{
Every bite counts!
}

\author{
Maryam Heba
}

\section{Abstract}

The global food system is a major contributor to climate change, producing 19 - 29 per cent of greenhouse gas emissions (Vermeulen, et al., 2012). This system is entirely controlled by humans, and therefore, we are responsible for the negative effects of this system on the well-being of our planet. The large amount of greenhouse gas emissions occurs mainly due to food miles - the distance that food is transported from producer to consumer - and our meat consumption. In this research-informed action report I conducted a study to: i) determine if there was correlation between gender and meat consumption; and ii) if there was a correlation between gender and purchasing of locally grown foods. I learned that 67 per cent of high school boys and 71 per cent of girls that I surveyed consumed meat more than 4 times a week. Based on this data, I concluded that there was no correlation between gender and meat consumption amongst teenagers that I surveyed. However, I felt that meat consumption was rather high. Also, about 40 percent of boys and girls sometimes buy locally grown food, which is great, but a third of them did not know if the food they, or their parent, purchase is locally grown. Once again, I concluded that there was no correlation between gender and habits of purchasing locally grown foods. In repose to this, I decided to take an action and develop a video to make my peers more aware of global food systems and their relationship to climate change. I posted the video on FaceBook ${ }^{\mathrm{TM}}$ where my family and friends can view it and comment. I hope that this project inspires everyone to be more conscious about their diets and that we can collectively reduce the GHGs through reduced meat consumption. 


\section{Introduction}

Food is necessary for our survival, but have we gone too far in terms of our food consumption, especially in the Western Hemisphere? Are we causing more harm to our planet through our increased global food consumption?

Transporting food is one of the fastest growing sources of greenhouse gas emissions. Each year 817 million tons of food is shipped around the planet releasing a colossal amount of greenhouse gases, specifically CO2 (Diet for a Hot Planet, n.d.). The average meal travels 1200 kilometers from a farm to plate (Centre for Environmental Education, 2008). The combustion of fossil fuels releases greenhouse gases in our atmosphere and this contributes to the anthropogenic greenhouse effect. Furthermore, meat consumption contributes significantly to GHGs and climate change. Livestock alone are responsible for $18 \%$ of all greenhouse gas emissions (David Suzuki Foundation, n.d.). Human beings cannot blame livestock for this, as it is a part of their natural digestive system. In fact, through industrial farming, many farmers have altered the digestive system of livestock thus concentrating livestock's emissions of methane. I recommend the video encoded in the QR to better understand the negative impacts of of industrial farming. The video contains several disturbing scenes that may not be suitable for everyone. Negative consequences of climate change, such as heat waves, droughts and floods may be reducing crop yields leading to starvation and malnutrition to individuals in developing or underdeveloped countries, especially in Africa. This crop reduction may induce economic stagnation in numerous countries due to people losing their jobs in the food industry, such as cotton farmers in India. Moreover, excessive farming of crops, especially corn, causes loss of topsoil 17 times faster than the regular rate (Food \& Agriculture - ChartsBin.com., n.d.) This not only decreases possibility of plant life, but it also effects the soil's efficiency as a carbon sink.

We need a collective approach to address some of the issues related to global food production. We need our governments, food industries and other key stakeholders to work together and recognize that we need a change. As high school students, we can alter our food consumption. We can become more aware of what we eat and how it affects not only our wellness, but also the well-being of our entire planet. I call for action! Every bite counts when it comes to the wellbeing of individuals, societies and environments.

\section{Focus Of Our Study}

The focus of my study was to find out if there is a correlation between gender and daily diet habits at our school. I devised a survey asking my peers about their weekly meat consumption and the purchasing habits of locally grown foods. I collected the data over lunch break from 50 girls and 50 boys who attend Erindale Secondary School. 
Table 1: Students' Frequency of Meat Consumption in Erindale Secondary School: 50 boys and 50 girls were asked how often they consume meat per week. 67 per cent of high school boys and 71 per cent of girls that I surveyed consumed meat more than 4 times a week. This represents a high weekly meat intake for both genders.

\begin{tabular}{|c|c|c|c|c|c|c|c|}
\hline \multicolumn{2}{|c|}{0 times } & \multicolumn{2}{c|}{$1-3$ times } & \multicolumn{2}{c|}{$4-6$ times } & \multicolumn{2}{c|}{7 times } \\
\hline Girls & Boys & Girls & Boys & Girls & Boys & Girls & Boys \\
\hline 3 & 3 & 11 & 12 & 14 & 24 & 20 & 9 \\
\hline
\end{tabular}

\section{Summary and Interpretation}

The results of this study reveal that boys' and girls' meat eating habits at Erindale Secondary School do not contrast that much from one another. Surprisingly, more girls reported that they consume meat every day compared to boys. However, I should note that this study is biased. One thing is for sure: over two thirds of boys and girls consume meat more than 4 times per week. Perhaps at this age, when we are growing and developing, it is normal to consume so much meat; however, I would argue that this still represents a large number of students whose diet is meat-based.

Furthermore, there appears to be no correlation present between male and female purchasing habits of locally grown foods. $71 \%$ of the male teens at Erindale are aware of where their groceries come from, while $73 \%$ of the female teens at Erindale are also aware. Overall, $14 \%$ of the students are not aware whether their groceries are local or not. Although the number may not appear alarming, efforts should be made to raise awareness of the correlation between diet and climate change so that students are also engaged to buy locally more often. Students should be engaging their parents about this critical issue as well, as most parents buy food for their kids at this age.

By doing this project, I became aware about the issue of diet and climate change. If one was to ask an average teenager what we should do to mitigate the effects of climate change, they may provide a list of actions, including riding a bicycle instead of a car, turning off lights, etc., but most likely they will not mention purchasing local groceries or eating less meat. This may be due to lack of awareness, or even maybe denial by powerful stakeholders, who do not necessarily announce to the public the negative consequences that food industry is having on climate change. Although I did not question the level of awareness of my participants with regards to how diet and climate change relate, I speculate that those who consume meat 0-3 times per a week and often purchase locally grown foods have a well-founded awareness of the influences of their dietary choices on the environment. 
Table 2: Purchasing Habits of Locally Grown Foods in Erindale Secondary School: 50 boys and 50 girls were asked about their (or their parents') shopping practices in terms of purchasing locally grown foods. The data indicates that there is no correlation between gender and purchasing practices. About 30 percent of boys and girls do not know if their food is locally grown/ produced.

\begin{tabular}{|c|c|c|c|c|c|c|c|}
\hline \multicolumn{2}{|c|}{ Never } & \multicolumn{2}{c|}{ Sometimes } & \multicolumn{2}{c|}{ Often } & \multicolumn{2}{c|}{ I don't know } \\
\hline Girls & Boys & Girls & Boys & Girls & Boys & Girls & Boys \\
\hline 6 & 7 & 18 & 18 & 10 & 10 & 14 & 13 \\
\hline
\end{tabular}

\section{Taking Action}

One of the other goals of this project is to raise awareness about this issue through action! This project serves to promote personal, social and ecological wellbeing. Watching what we purchase and eat will improve our health, support your communities financially, and reduce the destruction of our only planet. Decreasing meat consumption, especially meat that has been imported from factory farms, starting a community garden that will bring people together, and buying more locally grown food are some ways in which we can begin to have a positive impact on our individual, social and ecological wellness. These actions should be our duty. As the citizens of the developed countries, we tend to have an abundance of technology and resources, meaning we have the tools to reverse the negative impacts of climate change. As part of my effort to make a difference, I developed an awareness video summarizing what I learned in this project. I shared the video with my friends and family of FaceBookTM, and I received some encouraging comments that made me feel that my efforts have started to pay off. 

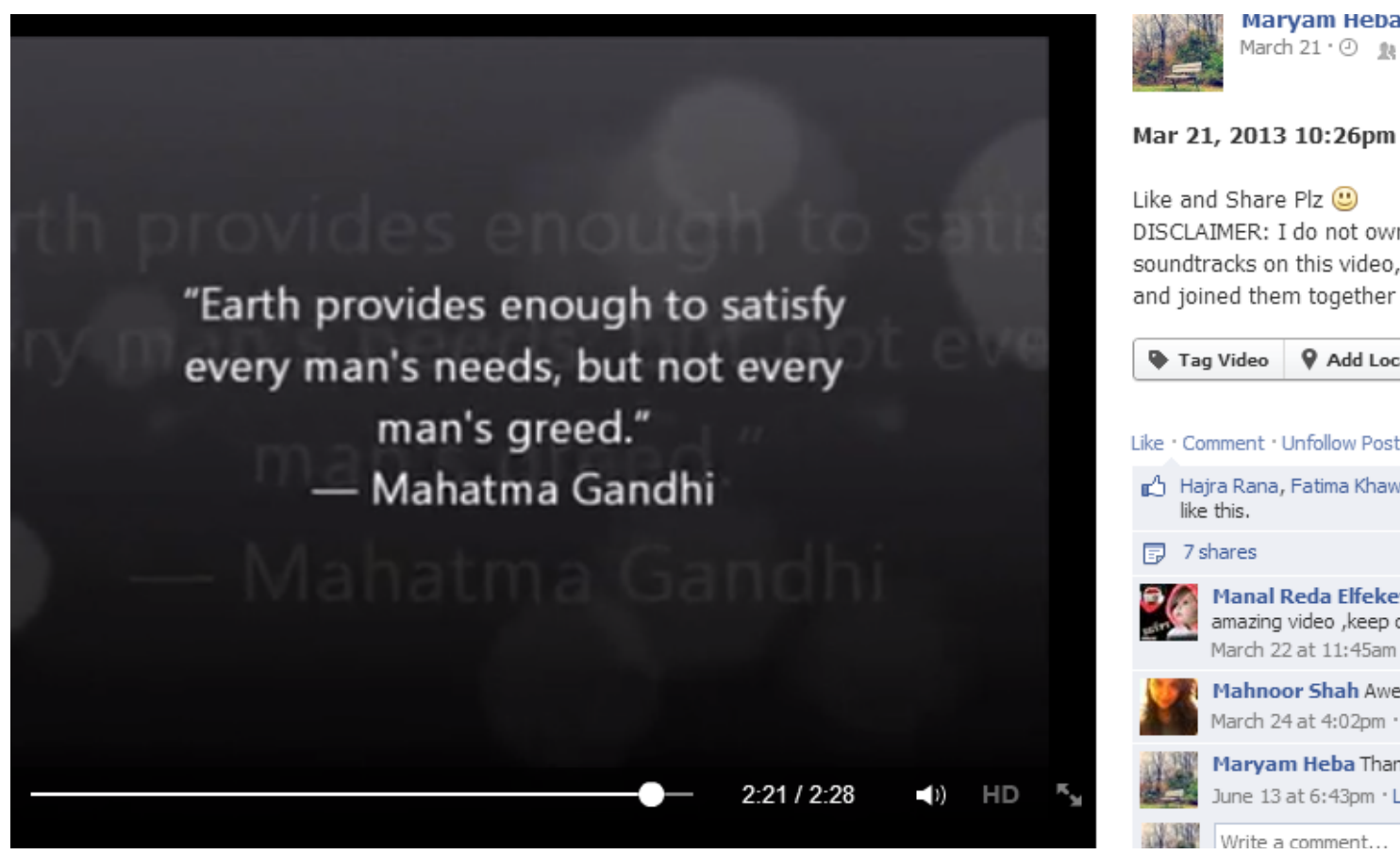

Mar 21, 2013 10:26pm

Like and Share Plz (:)

DISCLAIMER: I do not own any of the clips or soundtracks on this video, I simply gathered the clip and joined them together with the soundtracks.

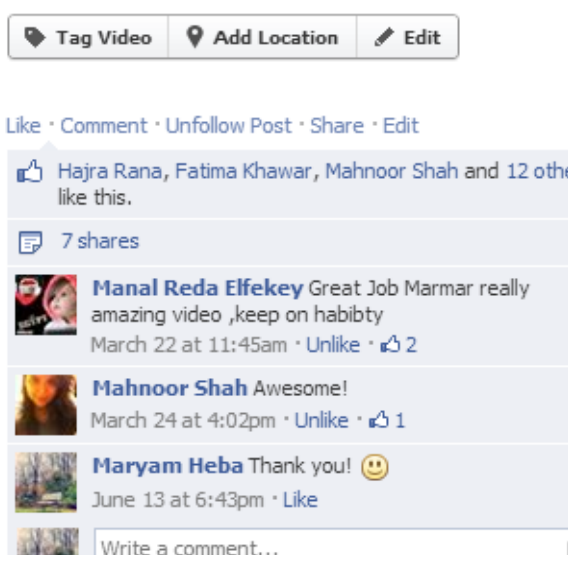

\section{References}

Diet for a Hot Planet. The New School [Video file]. (n.d.). Retrieved from http://www.youtube.com/watch?v=S08cRsCX8qQ

Centre for Environmental Education (2008). Retrieved from http://www. ceeonline.org/greenGuide/food/upload/environmenthealth.aspx

Food and climate change | Food and our planet | Reduce your carbon footprint | What you can do | David Suzuki Foundation. (n.d.). Retrieved from http://www. davidsuzuki.org/what-you-can-do/food-and-our-planet/food-and-climate-change/

Food \& Agriculture - ChartsBin.com. (n.d.). ChartsBin.com - Visualize your data. Retrieved February 24, 2013, from http://chartsbin.com/graph/food_and_agriculture

Food and climate change. David Suzuki Foundation. (n.d.). Retrieved from http://www. davidsuzuki.org/what-you-can-do/food-and-our-planet/food-and-climate-change/

Vermeluen, S. et al. (2012). Climate Change and Food Systems. Annual Review of Environment and Resources. Vol. 37, p.195-222. Retried from: http://www.annualreviews.org/ doi/abs/10.1146/annurev-environ-020411-130608 